\title{
Reducing the Difference between Citizens and Consumers: A Critical Discourse Analysis of the Communications White Paper 2000
}

\author{
SIMON DAWES, Nottingham Trent University
}

\begin{abstract}
By conducting a Critical Discourse Analysis (CDA) of the Communications White Paper 2000, this article demonstrates the processes by which the government has socially and discursively reconstructed the public service ethos of broadcasting and the relations between citizenship and consumerism. Focussing on the occurrences of the citizen- and consumer-signifiers, the analysis confirms the claims of critical social theorists that there has been a shift in the government's conception of the public from citizens to consumers. However, by adopting a cross-disciplinary methodology to the analysis of the texts, the complex processes and tensions involved in this shift can be made manifest, and the ways in which the differences between public and private oppositions are rhetorically reduced - so that the consumer becomes an active agent, able to act collectively, while the citizen becomes a passive individual - can be demonstrated.
\end{abstract}

\section{KEYWORDS}

citizen; consumer; public service broadcasting; critical discourse analysis.

\section{Introduction}

Media and academic debate on the future of broadcasting is commonly split between the argument for the continued significance of public service broadcasting to citizenship in liberal democracies, and the insistence upon the legitimacy of the market as a guarantor of consumer sovereignty. The Third Way rationale of the New Labour government, however, claims to transcend this public-/private-interest dichotomy, or citizen/consumer divide, by realising that 'we', as the public, are both citizens and consumers, and by addressing the regulation of broadcasting in the context of our interests as citizens and as consumers. In this article, I will argue that not only is this balance between the interests of citizens and consumers, in the government's literature on the role of broadcasting, weighted in favour of the consumer, but that the terms 'citizen' and 'consumer' have themselves been redefined, and the difference between them reduced, to the extent that any claims to 'transcendence' are purely rhetorical.

Drawing, in particular, on Graham Murdock's work on the political economy of the media, I locate his arguments in the work of Jürgen Habermas on the shift in 
influence from public to private realms. Murdock argues that there has been a shift in the rationale of communications policy, from one of public interest to one that seeks to extend corporate logic, and analyses this in terms of the decline of the public service ethos in broadcasting and the increasing influence of the market (Murdock, 1999, p.39). However, in calling for more interdisciplinary work into this area of investigation, he suggests that the liberal agenda of de-regulation represents more of a re-regulation of the sector, and a redefinition of public service, rather than a reduction, as such, in the number of rules (Murdock, 1993, p.12).

Arguing that much of critical social theory informed, media studies literature tends to oversimplify the development of broadcasting in the UK as that of a transition from a public service to a commercial market (and from constructing the public as citizens to constructing them as consumers), I have opted for a cross-disciplinary approach to the study of the social and discursive changes to broadcasting regulation. Drawing on Critical Discourse Analysis (CDA), which argues that change is socially and discursively produced, the processes by which the contemporary government has reconstructed the public service ethos and the relations between citizenship and consumerism can be demonstrated. By conducting a CDA of the Communications White Paper 2000, my analysis focuses on the occurrences of the citizen- and consumer-signifiers and the terms with which they are collocated, and through comparative analyses of the White Paper with earlier (The Report of the Annan Committee, 1977) and later (Ofcom's PSB Review, 2004) texts, I confirm the claim of critical social theorists that there has been a shift in the government's conception of the public, from citizens to consumers. However, by adopting this cross-disciplinary methodology to the analysis of the texts, the complex, discursive processes and tensions involved in this shift - which are normally overlooked by a purely social approach - are made manifest.

The article is split into four sections. The first outlines the literature from media studies and critical social theory on the social changes to broadcasting in the UK. The second section introduces and explains the concept of discursive change, while the third details the cross-disciplinary methodology of the research undertaken. The fourth section summarises the results of the CDAs of the three texts, and interprets the findings in light of the literature on social change.

\section{The Social Changes to Broadcasting in the UK}

When broadcasting began in the 1920s, the models upon which the UK and US systems were based were ideologically opposed. While, in the words of Graham Murdock, the US adopted a commercial model, whereby private companies 'made profits by packaging audiences for sale to advertisers and beckoned their viewers and listeners to join the democratic community of consumers,' the UK developed a public service model, whereby a licence fee funded a public corporation which 'didn't take advertising and which addressed audiences as members of a national and imperial community' (Murdock, 1999, p.31). These models offered the overarching identities for the viewing public of the 'citizen' and the 'consumer'.

Traditionally, these terms have denoted either the public or the private realm. Nicholas Garnham makes the following distinction: 
Within the political realm the individual is defined as a citizen exercising public rights of debate, voting etc, within a communally agreed structure of rules and towards communally defined ends. The value system is essentially social and the legitimate end of social action is the public good. Within the economic realm on the other hand the individual is defined as producer and consumer exercising private rights through purchasing power on the market in the pursuit of private interests, his or her actions being coordinated by the invisible hand of the market

(Garnham, 1990, p.110)

Over the course of the twentieth century, however, this dichotomous relationship between the public service and the corporate approaches to broadcasting became less distinct in the development of alternative channels in the UK. Following accusations that the BBC was condescending towards the working classes and was failing to provide popular entertainment, the 'half-way house' between public and corporate financing of ITV was introduced. Then, with the so-called 'crises of representation' in the 1970s, whereby the BBC was accused of failing to represent the interests of minority national groups, the attempt to redress this balance by the creation of a fourth channel coincided with broadcasting's acceleration into the corporate system (Murdock, 1999, p.33).

It was in this context that the Annan Committee met in 1977. Discarding 'imagined unities of national culture' and abandoning the commitment to an undivided public good, they embraced Britain as 'a fractured cultural formation' and replaced the ideal of public service with the principle of liberal pluralism (Curran and Seaton, 2003, p.304; and Murdock, 1999, p.33). Breaking with the Pilkington Report's hostility towards advertising, the Committee proposed that, while the new channel (Channel 4) should "address constituencies of interest that were under-represented in mainstream terrestrial programming" (Murdock, 1999, p.34), it should also be funded by a mixture of advertising revenue and public funds. Murdock regards this contradiction as a source of tension in the way the channel constructs and represents difference. "The remit clearly works with a conception of social interests whilst advertisers work with a map of market niches" (Murdock, 1999, p.34). The distinction between the two overarching identities of 'citizen' and 'consumer' becomes, therefore, significantly blurred.

Yet from the early 1990s, and throughout the Major government, users of public services were depicted in government policy as citizens (Keat, Whitely and Abercrombie, 1994, p.15), and their rights to decent standards of public services were set out in charters such as John Major's Citizen's Charter 1991. Murdock, however, argues that this equated citizenship rights with consumer rights (1999, p.29). Nonetheless, the representation of consumer rights in terms of citizenship does not necessarily exclude other aspects of citizenship rights (that is, a citizen's 'rights of everyday life', as discussed below); rather, a conceptual space for these rights is left remaining. There exists, though, the possibility that this space could be filled by 'consumerist redefinitions of non-market forms of citizenship,' which would lead to confusion over the distinction between consumer sovereignty and the position of the citizen in the political sphere (Keat, Whitely and Abercrombie, 1994, p.15). The analysis carried out for this article focuses on the ways in which the New Labour 
government has attempted to fill this 'conceptual space' and to address these 'rights of everyday life'.

Drawing on the work of TH Marshall, Murdock identifies four 'clusters' of rights that are constitutive of the ideal type of citizenship that emerged alongside the development of mass media communication. To the civil (freedom of belief and action, from torture and arbitrary detention) and political (the universal franchise and jury system that allows individuals to participate in the laws under which they are governed) rights of the nineteenth century, the socio-economic and informationcultural rights of the twentieth were added. Murdock argues that socio-economic (employee, consumer and welfare) rights are the minimum material basis for the exercise of civil and political rights, and that information-cultural rights are important for securing the symbolic and discursive resources necessary for the exercise of citizenship. More specifically, while information rights require that the fullest range of information is provided within a framework of arguments and concepts (not simply that all information is made available, but that all relevant information is made available alongside informed opinions from a range of perspectives), cultural rights signify that complex spaces should be made available within which individuals can recognise themselves and affirm themselves for what they wish to be (Murdock, 1999, pp.29-30) (This could refer, for example, to relations of the body, whereby women and ethnic minorities have a right to see their existence in society confirmed and their interests and tastes expressed). "These rights of representation are what (Alberto) Melucci calls "rights of everyday life" in the sense that they relate to social identities that cannot be neatly subsumed within the master-categories of "citizen" and "consumer" (Murdock, 1999, p.30), so blurring the traditional boundaries between public and private. The complexity of these social identities and the significance of these 'rights of everyday life', contribute towards a tension in the way that communicative and representative rights are addressed in government literature on broadcasting policy.

Media Studies literature on the development of broadcasting in the UK demonstrates, through a focus on changes in regulatory policy, ownership and technology, the tendency towards an increasingly commercial model, the increasing influence of the commercial sector, and the increasing and contemporary preference for the term 'consumer' over 'citizen' in regulatory documents (Curran and Seaton, 2003; and Murdock, 1993, 1999). This literature is often informed by critical social theories, and draws particularly on Jürgen Habermas' work on the public sphere; often represented as an ideal type for a public service broadcaster. The shift from an emphasis on public service to one of consumer sovereignty is often placed in the context of Habermas' claim that the extension of the market into the domain of everyday life corresponds with a shift in the flow of influence on the commonsense assumptions of everyday life. He argues that whereas this flow of influence was once from the sociallyintegrated (public) to the system-integrated (private) institutions, it has now been reversed through the continual extension of the market; and, consequently, that the influence of the economy, self-interest and the private realm now outweighs that of society, culture and the public good (Habermas, 1996). The significance of the mass media communications sector lies in both the role it plays in organising the symbolic world (where the 'rights of everyday life' can be guaranteed), and in its position as a link between the economic structures and cultural formations of modern capitalist societies. According to Murdock, however, the mass media communications sector is 
inherently contradictory in the way that it connects a '...productive system rooted in private ownership to a political system (of) a citizenry whose full social participation depends in part on access to the maximum possible range of information and analysis, and to open debate...' (Murdock, 1993, p.4 - emphases added), echoing Habermas' insistence upon the influence of private interests.

Recognising, however, that change is discursively, as well as socially produced, an analysis of the language used in the regulatory texts, interpreted in the context of these theories of the social changes to broadcasting, offers the possibility of a more in-depth understanding of the processes involved in this shift.

\section{Analysing Discursive Change}

It is widely accepted that language is inherently important in politics and in communication media (Thompson, 1990), and that, it has been argued, it plays an increasingly important role in the contemporary era due to a shift in the social functioning of language (Habermas, 1996). In discussing the colonisation of the 'lifeworld' by the 'systems' of the economy and the state (or the usurpation of the public realm, as the primary source of influence on the common sense assumptions of everyday life, by that of the private), Habermas has emphasised the displacement of 'communicative' uses of language - oriented to producing understanding - by 'strategic' ones - oriented to success and manipulation. This displacement has been located in the context of an extending market (Stevenson, 2003, p.97), which has reconceptualised activities as the production and marketing of commodities for consumers - affecting activities, social relations and the social and professional identities of those involved in the sectors of society undergoing such reconceptualisation (Fairclough, 1992, p.6). The post-Fordist production discourse in industry, for example - of flexible relations in a fast moving process, where workers are defined in terms that had previously belonged to the private sphere - leads to a tension between local, or national, traditions and a new global order (Fairclough, 1992, p.7). If the language of government could be shown through discourse analysis to have become more strategic than communicative, then the ways in which they discuss, for example, communicative and representational rights (the 'rights of everyday life') would have significantly altered also; with these rights being represented in private terms with little or no regard for the public good.

While language studies and social theory have traditionally treated texts as finished products in themselves, reflective of external, social processes, some contemporary branches of the two disciplines have begun to alter their conceptions of texts. For example, some branches of language studies, discourse analysis, in particular, emphasise the processes of production and interpretation, and the situational contexts in which texts are produced and interpreted. In this case, texts become only one dimension of discourse - the written/spoken product of processes of text production and the social effects of discourse become a further addition to the linguist's object of study. Likewise, some social theorists see discourse as a way of structuring knowledge and social practice, and as a type of language specific to a social situation (advertising discourse, for example). As such, discourses do not reflect or represent social entities or relations, they construct or constitute them. Further, different discourses constitute key entities - such as citizenship and consumerism - in various 
ways, and position people in various ways as social subjects - such as citizens or consumers (Fairclough, 1992, p.4).

Furthermore, discourses construe the world in selective and reductive ways, and they do not do so at random, nor are they in arbitrary relation to social practices and structures. By locating discourse in the context of social change, particular representations can be connected with particular interests and relations of power. Put simply, in the social context of privatisation and liberalisation, whereby power is transferred from the public to the private corporations, the corresponding representation of the consumer subject position over that of the citizen could be connected with the influence of corporate interests.

However, the causal relations of social change are not simple or one-way. While it is easy to see how non-discoursal elements can bring about changes in discourse, it is harder to accept that change can be discourse-led, which, Fairclough argues, is a pervasive contemporary change. This change is initiated through dialectical processes, such as the recontextualisation of external discourses within a new field (such as the incorporation of corporate discourse into that of government), which are 'enacted in new ways of inter/acting,' 'inculcated as new ways of being' and 'materialised as new ways of organising space' (Fairclough, 2004a, p.3). Through a historical analysis of contemporary communications documents, therefore, one would expect to see a change in the way that audiences are referred to - with the term 'viewers' being more frequently replaced by the term 'consumers' or 'customers.' These processes are, however, contingent on the ways in which they are resisted and accepted, so that there is often a tension within texts between the various ways of addressing subjects; Fairclough points out that these tensions are particularly evident in the language of New Labour, as the tendency to construct the public as consumers is resisted by their own supporters, and even by politicians within the (traditionally left-wing) party itself (Fairclough, 2000).

\section{Critical Discourse Analysis - A Methodology}

Critical Discourse Analysis (CDA) is a cross-disciplinary approach to the study of texts, which views language as a form of social practice, and discourse from a realist perspective. Realists see discourse as one element of social events and practices, subsuming language as well as other forms of semiosis (such as body language and visual images). Texts are seen as the discoursal elements of social events, and the points of articulation and tension between practices and structures. Through the analysis of texts, the active construction of discourse can be made manifest. Within texts, social change can be 'diagnosed' through the analysis of how 'discourses,' 'genres' and 'styles' are drawn upon and articulated together.

The analysis of texts as instances of socio-cultural practice can, nevertheless, bring to the fore the connections between language, power and ideology that may be hidden in articulations of commonsense assumptions (Fairclough, 1989, p.4). CDA aims to deconstruct such assumptions as ideologies, seeing them as dependent upon the underlying social relations and differences of power that they serve to legitimise through the recurrence of the ordinary and the everyday (Fairclough, 1989, p.2). As commonsense assumptions are most relied upon through language, the commonest 
form of social behaviour, it is through a critical analysis of texts that deconstruction can most effectively be achieved.

CDA sees texts as constitutive, in part, of social change. They are not finished products, in themselves, but rather elements of the relationship between social and discursive change. Power relations are hidden within texts beneath common sense assumptions, which, in turn, legitimise such relations through their familiarity. Deconstructing these assumptions and identifying the presence of an external discourse can reduce the gap between the rhetoric of a text and the reality of the social changes it constitutes.

However, as these processes are contingent on the ways in which they are resisted or accepted, there is often tension between the discursive oppositions a text constructs. Further, discursive change is rarely linear - often involving a series of contradictions and tensions that arise through the overlapping of discourses. Social theory does not account for such tensions, and, even when it sees social change as discourse-led, tends to regard texts as finished products.

CDA views texts as elements in the relationship between social and discursive change: texts are unfinished products; discourses change over time; and power relations are hidden beneath commonsense assumptions (Fairclough, 1989, 1992, 2000). Analysis of texts can reveal points of tension and identify ideological preoccupations. In conducting a CDA of the Communications White Paper 2000, it is possible to explore the complexity of the shift in the construction of the public. For the analysis to be historical - to demonstrate how the discourse has changed over time - I will also be comparing the findings from the White Paper (which set out the objectives of the new meta-regulator, Ofcom) with those of an earlier text (The Report of the Annan Committee, from 1977, mentioned earlier) as well as a later text (Ofcom's PSB Review, from 2004).

\section{Summary and Interpretation of the Analyses}

In the White Paper, the consumer-signifier (that is, the term 'consumer') occurs three times more frequently than that of the 'citizen', although the text is preoccupied with addressing the needs of 'both citizens and consumers', with the two signifiers appearing repeatedly side by side. The paper is split into sections that deal specifically with citizen issues, on the one hand, and consumer issues, on the other. It is apparently explicit in distinguishing between what constitute citizen or consumer interests, and deals with them in contrasting ways. If a citizen issue needs dealing with, Ofcom (the independent regulator that this white paper established) will investigate the service provider responsible and intervene directly. If it is a consumer issue, it will act indirectly through manipulating market mechanisms.

In contrast, in the Annan Report of 1977, 'the public' is the ubiquitous subject position, synonymous with 'citizens', with 'citizen' denoting the individual. In one chapter, entitled the 'Role of Broadcasting', 'public' appears 10 times, and 'citizen' 4 times, while 'consumer' is absent. Consumer issues are discussed only in the context of programming, and refer uniquely to programmes about shopping and consumer watchdog programmes built around complaints. In the 522-page document, only 1 
page is devoted to 'consumer programming', the same amount devoted to 'programmes for handicapped people', and in which 'consumer' appears 12 times, while 'citizen' and 'public' are absent. This chapter does not deal with citizens or the public, but only with consumers. The distinction, throughout this earlier text, between public and private, and the emphasis on public over private interests, are made clear, and the consumer is constructed, therefore, as a type of citizen, as a citizen in the act of consumption, and, in the context of broadcasting, in a negative relation to the service providers.

In the White Paper, however, within this context of programming, citizens are referred to in terms of news and current affairs, while consumers are discussed alongside TV more generally. The Paper constructs the public as primarily, or always-already, consumers, who only become citizens (a type of consumer) when they watch the news.

The objectives of the new regulator, as laid out in the White Paper, are threefold:

We [the government] propose that OFCOM's central regulatory objectives should be:

- protecting the interests of consumers in terms of choice, price, quality of service and value for money, in particular through promoting open and competitive markets;

- maintaining high quality of content, a wide range of programming, and plurality of public expression;

- protecting the interests of citizens by maintaining accepted community standards in content, balancing freedom of speech against the need to protect against potentially offensive or harmful material, and ensuring appropriate protection of fairness and privacy.

(Section 8.5: Regulatory Objectives, emphases added)

In setting out the future regulator's objectives, the White Paper constructs some very clear distinctions between the interests of citizens (in the third bullet-point) and those of consumers (in the first) - while abandoning the set of interests listed in the second bullet-point to a limbo-state, a murky, 'grey area' in between the interests of citizens and consumers, and outside of both public and private realms (see Figure 1 for an illustration of these three spheres of interest). 


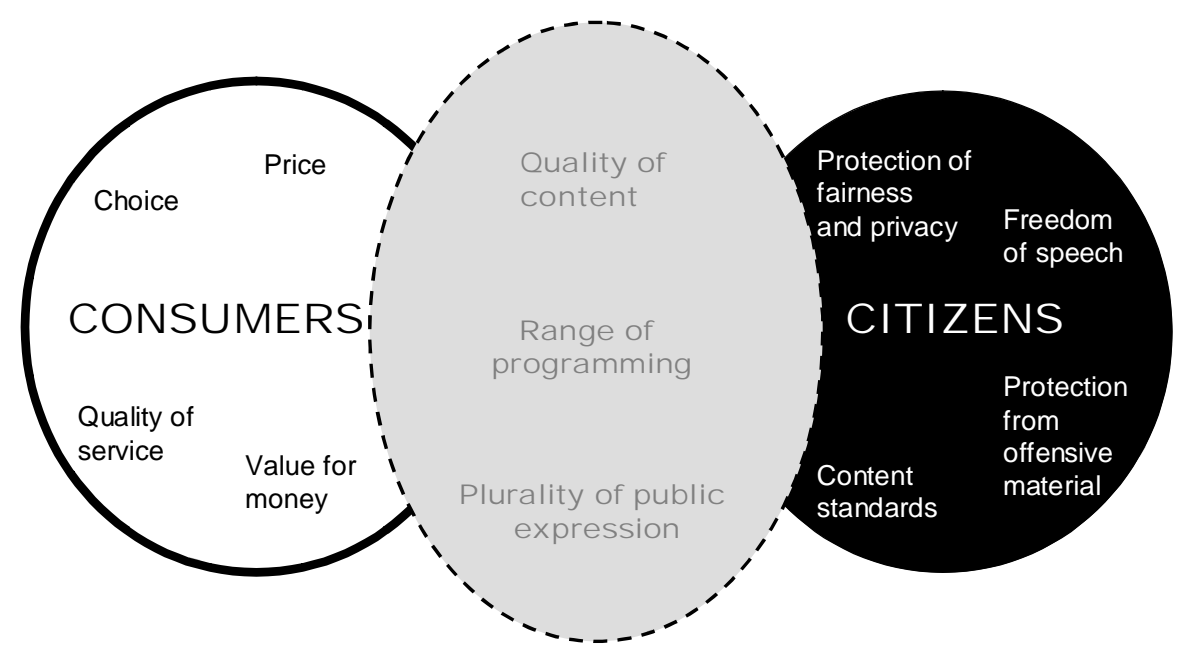

Figure 1: The three spheres of interest (consumer; citizen; and the 'grey area in between').

Choice, price, service quality and value for money are defined as consumer-interests. Content standards, freedom of speech, protection from offensive or harmful material and of fairness and privacy are clearly defined as citizen-interests. While consumer rights are addressed, therefore, by constructing consumers in terms of their financial relationship with service providers, the terms in which citizenship is defined - within a framework of legality - limit the regulator to addressing civil rights alone, and fail to consider a citizen's rights of representation, or 'rights of everyday life'. Further, while the interests of the citizen will be served directly by an independent regulator, those of the consumer will be dealt with indirectly through the regulator's promotion of 'open and competitive markets'. It is important to emphasise, therefore, that the discursive construction of, for example, content standards and service quality as, respectively, citizen and consumer interests, determines the way in which they are to be regulated by Ofcom - whether through direct interference in the way a service provider operates, or through the indirect manipulation of the market.

As they are not attributed to the interests of either citizens or consumers, however, the way in which the interests indicated in the second bullet-point will be dealt with is much more ambiguous. Quality of content is made distinct from content standards (which are dealt with directly by the regulator as citizen-interests), and from quality of service (which is dealt with indirectly through the market as a consumer-interest). The range of programming (distinct from the quality or content of programming) and the plurality of public expression also fall into this grey area that the government is unable, or unwilling, to subsume under the banner of either citizen or consumer interests, constituting points of tension that pervade throughout the text (see Figure 2 for an illustration of the discursive distinctions between these three spheres of interest). 


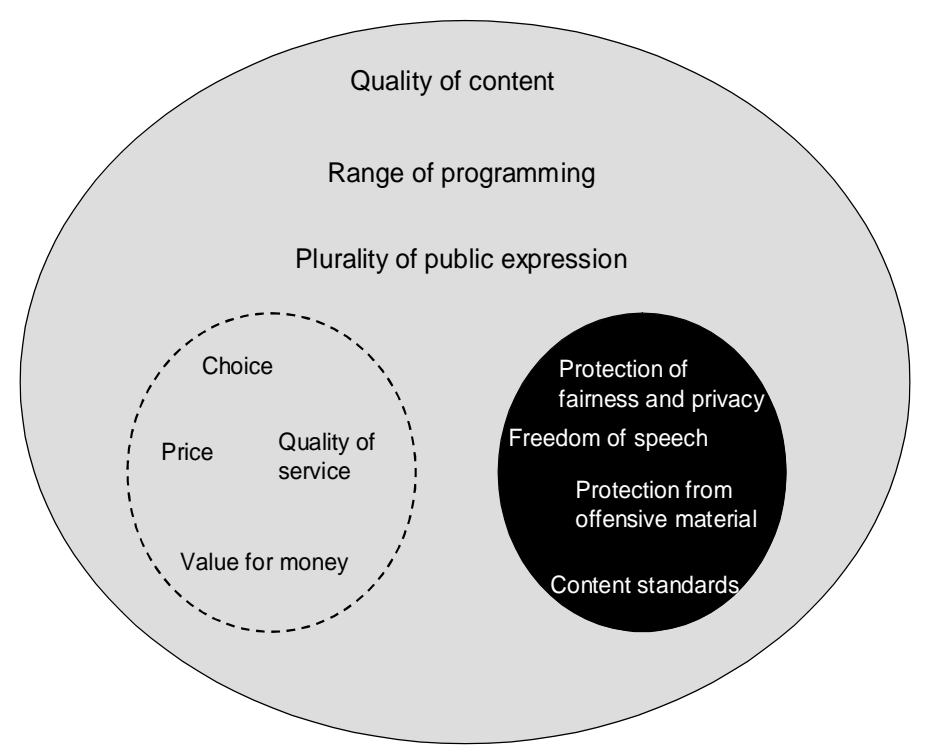

Figure 2: The grey area as public interest; the citizen and consumer spheres as individual interests within the sphere of public interest.

'Quality' becomes a fuzzy concept; the 'quality of broadcasting' (as referred to in Section 5 of the White Paper, entitled Securing Quality), unless otherwise stated, could refer to the quality of either content or service provision. The use of the term 'plurality' is similarly ambiguous; in a section devoted to plurality, it is the 'diversity and plurality of communications services' that is discussed, rather than the plurality of public expression (this in Section 4, 'Maintaining Diversity and Plurality'). Although the objective of maintaining a 'high quality of content, a wide range of programming, and plurality of public expression' correspond with the meeting of requirements for a citizen's rights of representation or everyday life, they are not included as citizen-interests in the text, and, therefore, 'Securing Quality' and 'Maintaining Diversity and Plurality' may not either (see Figure 3 for an illustration of how the 'citizen' and 'consumer' spheres of individual interest are subsumed within the sphere of 'public' interest').

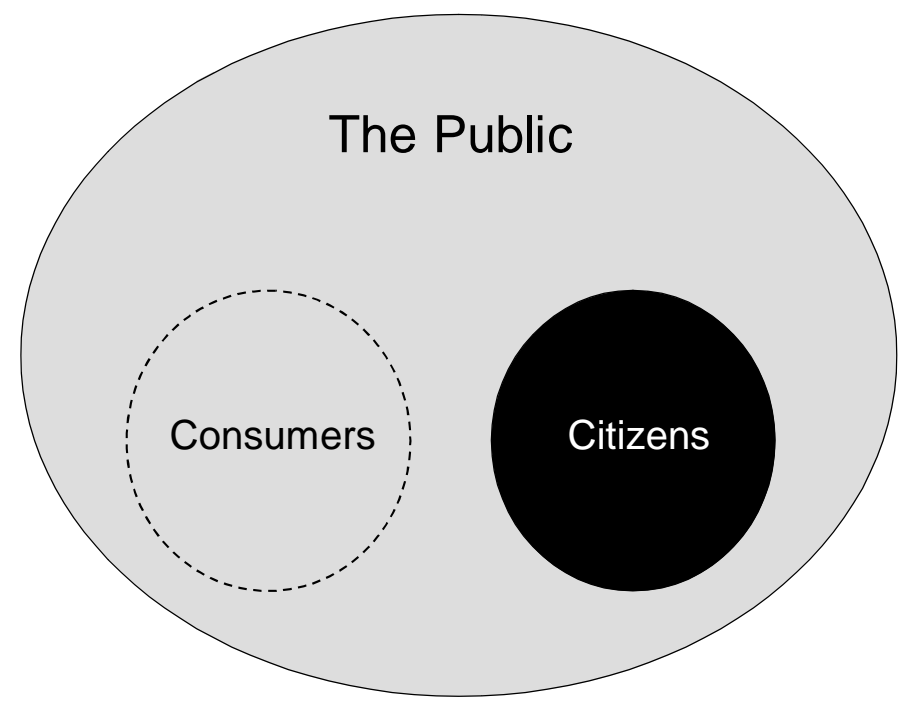

Figure 3: Citizens and consumers as individual members of the public. 
However, when the terms 'quality' and 'plurality' are qualified or located - that is, when a signifier is used in the fuzzy context of quality and plurality - it is the consumer-signifier. But because the White Paper has already set out the definitions of 'citizen' and 'consumer' interests, this necessarily involves a secondary usage of the consumer-signifier, one which extends the connotations of consumerism beyond the limitations of direct, financial relations, and into the sphere of everyday, public life.

So, rather than the area of interest indicated in the second bullet-point being a murky, grey area in between the interests of citizens and consumers, it relates instead to 'the public' in an 'everyday' sense; a public realm of everyday consumers, within which members of the public can act as individuals, in either citizen- or (financial) consumer-like ways. The meaning of the 'consumer' becomes contradictory, referring, on the one hand, in terms of choice, price, service quality and value for money, to an individual in a financial relation to service providers, and, on the other hand, in terms of quality of content, a wide range of programming, and plurality of public expression, to the 'public', or 'society as a whole'.

(See Figure 4 for an illustration of the contradictory usage of the term 'consumer'. I have distinguished between the macro and the micro connotations of 'consumer' by placing the macro, everyday life version 'under erasure', in a Heideggerian or Derridean way - because the ambiguity with which the term is used in this context suggests that the naming of the subject position is made out of deferral - that is, it is not quite correct, and is subject to ongoing reconstruction, but it is necessary for now.)

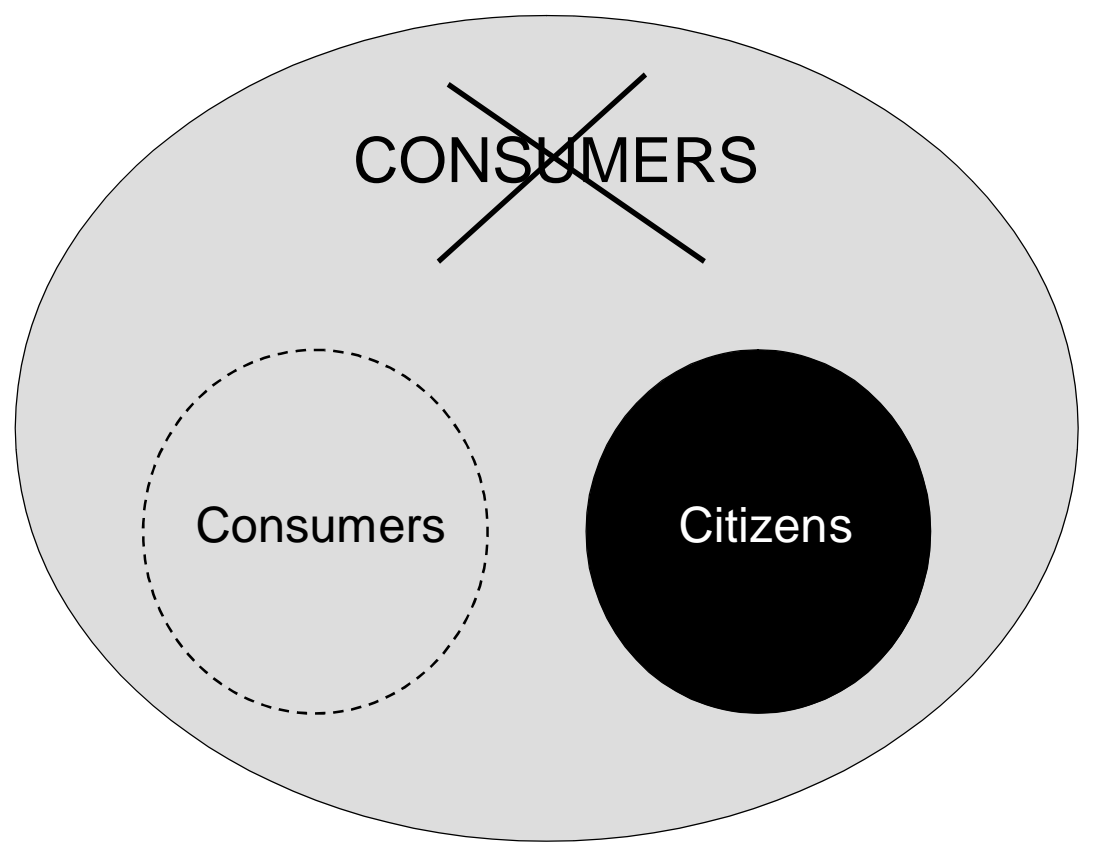

Figure 4: Two different types of consumer: a) as the individual, pursuing private interests and in a financial relationship with service providers; and b) as synonymous with the public. 
The public are constructed, therefore, as always-already consumers, able to act collectively in the sphere of everyday life; within this depoliticised public realm, the individual becomes an (inherently active) financial consumer when exercising choice in financial relations with service providers, or an (inherently passive) citizen when his/her civil rights are violated.

This expansion of the connotations of the consumer-signifier is repeated in Ofcom's Review of Public Service Broadcasting, published in 2004. The Review contrasts what Ofcom refer to as the social values-led and the economy-driven approaches to PSB regulation. While the former approach argues for strong regulation in the public interest, the latter argues for the extension of the market in the consumer's interests. The Review concludes, however, that these two, seemingly incommensurable, approaches are not so different; which is not so remarkable, when one understands that the regulator constructs PSB as only a sub-set of the public interest, 'alongside, for example, healthy competition, (and) a thriving commercial broadcasting sector...'. The commercial market becomes, therefore, less the antithesis of PSB, than its pre-requisite. Because of this similarity between the two approaches, Ofcom conclude that 'both approaches can, in fact, be captured in a wider economic framework which considers the maximisation of social welfare' (Phase One: The Definition and Purpose of PSB). Just as the White Paper reconstructs citizenship as part of consumerism, so the Review reconstructs public service in the context of an open and competitive market.

Another preoccupation of Ofcom's Review is with the ability of consumers to act collectively. The text refers to the Peacock Report's suggestion that 'consumers may have a considered view about the provision of aspects of broadcasting which they themselves might not directly consume' (A Research-Based View), and to the ITC's research into the extent to which the 'public' could 'separate their own personal programming likes and dislikes from their support for 'citizenship' or 'social/cultural' programming' (ITV1 Pilot Study). Significantly, the text distinguishes between the approach to regulation that has delivered to citizens what they 'want to be widely available for as many people as possible to watch,' and the approach that has delivered 'what consumers want to watch or want to have the option to watch' (Phase One: The Definition and Purpose of PSB - emphases added). The Ofcom text emphasises the impact of a consumer's private preferences on other consumers, and a consumer's awareness of this impact, thereby extending consumer choice beyond the scope of the individual, and equating consumers' collective action with the notion of a public realm. This process serves the purpose of reducing the difference between consumers and citizens, so that, on the one hand, the consumer can act collectively, and, on the other, the citizen can act individually.

\section{Conclusion}

In conclusion, then, there has indeed been a shift in rationale for the regulation of broadcasting in the UK, from one of serving the public interest and addressing citizens, to one of serving corporate interest and representing the public as consumers. However, by undertaking a CDA of some regulatory texts, it has been possible to identify the areas of tension within this ongoing discursive change, and to offer a more complex account of how this change is being brought about. 
This article has demonstrated how legal and financial rights are represented as areas of interest to citizens and consumers, respectively, while the 'rights of everyday life', which, as Melucci argued, cannot be subsumed under either banner, are represented as being in the public interest. However, in the first instance, this constructs both citizens and consumers as individuals (reconstructing citizenship in private terms), and, in the second instance, because of the contradictory dual use of the term 'consumer', reconstructs the 'public' in private terms. While the 'citizen' is limited to refer to an individual (not the public) in a passive and legal context, the 'consumer' refers to both an individual in an active and financial relationship, and also to the 'public as a whole'.

The 'consumer' has been reconstituted as an active agent with the ability to act collectively, while the 'citizen' has been reconstructed in increasingly individualistic (and passive) terms. By extending the private preferences of a consumer to the public realm, and by addressing the representative rights of a citizen in private terms, the government has discursively reduced the difference between public and private oppositions. Further, while an individual is constructed as either a citizen or a consumer, the public are constructed as always-already consumers.

This represents a tension in the government's literature on broadcasting, and exposes a preoccupation with filling that conceptual space for representing the public and addressing the 'rights of everyday life' outside of the traditional citizen-consumer dichotomy. The threat that this space could be filled by 'consumerist redefinitions of non-market forms of citizenship' (Keat, Whitely and Abercrombie, 1994, p.15) is being realised, but not without its complications and contradictions.

By applying a cross-disciplinary methodology to an analysis of the government's literature on broadcasting policy, the complexity of this process can be demonstrated, and the shift in ethos from one of public service to a more commercial outlook, can be better understood.

\section{References}

Couldry, N. (2004) The 'Productive' Consumer and the 'Dispersed' Citizen. International Journal of Cultural Studies. 7(1): 21-32

Curran, J. and Seaton, J. (2003) Power Without Responsibility: the press, broadcasting and new media in Britain, $6^{\text {th }}$ ed. London: Routledge

Fairclough, N. (1989) Language and Power. Harlow: Longman

Fairclough, N. (1992) Discourse and Social Change. Cambridge: Polity

Fairclough, N. (2000) New Labour, New Language? .London: Routledge

Fairclough, N. (2004 a) Dialectics of discourse. Available from: http://www.geogr.ku.dk/courses/phd/glob-loc/papers/phdfairclough2.pdf [accessed 18th July 2004] 
Fairclough, N. (2004 b) Global capitalism and critical awareness of language. Available from: http://www.schools.ash.org.au/litweb/norman1.html [accessed 18th July 2004]

Garnham, N. (1990) Capitalism and Communication: Global Culture and the Economics of Information. London: Sage

Habermas, J. (1996) The Structural Transformation of the Public Sphere: an Inquiry into a Category of Bourgeois Society. Cambridge: Polity

Keat, R., Abercrombie, N. and Whitely, N. (1994) The Authority of the Consumer. London: Routledge

Murdock, G. (1993) Communications and the Constitution of Modernity. Media, Culture and Society. 15: 521 - 539

Murdock, G. (1999) Corporate Dynamics and Broadcasting Futures. In: Mackay, H., O'Sullivan, T., eds. The Media Reader: Continuity and Transformation. London: Sage, 1980

Stevenson, N. (2003) Cultural Citizenship. Berkshire: Open University Press

Thompson, J.B. (1990) Ideology and Modern Culture: Critical Social Theory in the Era of Mass Communication. Cambridge: Polity

\section{Sources}

Home Office (1977) Report of the Committee on the Future of Broadcasting, March, (Lord Annan - Cmnd. 6753), London, H.M.S.O.

Department of Trade and Industry (2000) Communications White Paper, http://www.communicationswhitepaper.gov.uk (accessed between May 2004 and March 2005)

Ofcom (Office of Communications) Review of Public Service Broadcasting http://www.ofcom.org.uk/codes_guidelines/broadcasting/tv/psb_review/ http://www.ofcom.org.uk/consult/condocs/psb/?a=87101 (accessed between May and December 2005) 